\title{
Study to Assess Prevalence of Hemoglobinopathies by HPLC among Class IX and X Students of a Rural Block, Darjeeling District, West Bengal
}

\author{
Nilanjana Ghosh ${ }^{1}$, Indranil Chakrabarti ${ }^{2, *}$, Bidyut Krishna Goswami ${ }^{2}$
}

\begin{abstract}
Background: Hemoglobinopathies are commonest hereditary disorders in India. Hemoglobin $\mathrm{E}(\mathrm{HbE})$, in double heterozygous states with beta thalassemia trait may cause thalassemia, a fatal yet preventable disease. Its proven association with Rajbanshis, major ethnic group of this terrain has been well documented. Universally accepted preventive interventional strategies like screening tests for case and carrier detection remains the mainstay. Objectives: To determine prevalence of hemoglobinopathies among school going adolescents and find out their association with any defined ethnicity in the study area. Anemia was estimated. Methods: Descriptive cross sectional study was conducted from November 2015 to August 2016 in collaboration with Thalassemia Control Unit (TCU), North Bengal Medical College. It was intended to include all students of class IX and $X$ in the government run co-education secondary schools based on their current enrolment status, pertaining to study criteria. 1792 eligible subjects were studied. After ethical clearance and briefing, data was collected from screening camps organized in schools on prefixed dates, using appropriate tools and techniques and analyzed. Results: Prevalence of hemoglobinopathies was $44.5 \%$, major variants being $\mathrm{HbE}(22.6 \%)$, beta thalassemia trait (9.8\%) and E-beta thalassemia (7.3\%). Significant association was found between $\mathrm{HbE}$ hemoglobinopathies and Rajbanshis $(p=.00) .45 .2 \%$ study subjects were anemic. Conclusion: Hemoglobinopathies were substantially high in study area with $\mathrm{HbE}$ as commonest variant. Rajbanshis, a majority among study subjects were significantly associated with $\mathrm{HbE}$ hemoglobinopathies. Prevalence of anemia was alarmingly high. Planning preventive interventional strategies would ensure appropriate health behaviour of cases and carriers.

Key words: Screening, Hemoglobinopathies, Rajbanshis, Preventive strategies.
\end{abstract}

\section{Nilanjana Ghosh', Indranil Chakrabarti ${ }^{2, *}$, Bidyut Krishna Goswami}

'Department of Community Medicine, North Bengal Medical College, Siliguri, Darjeeling, West Bengal, INDIA.

${ }^{2}$ Department of Pathology, North Bengal Medical College, Siliguri, Darjeeling, West Bengal, INDIA.

\section{Correspondence}

Dr. Indranil Chakrabarti

Department of Pathology, North Bengal Medical College, Siliguri, Darjeeling,

West Bengal, INDIA.

Phone no: 9433187448

Email: drinch@rediffmail.com

\section{History}

- Submission Date: 08-04-2018

- Revised Date: 28-05-2018

- Accepted Date: 24-06-2018

DOI : 10.5530/ijmedph.2018.2.16

Article Available online

http://www.ijmedph.org/v8/i2

\section{Copyright}

(C) 2018 Phcog.Net. This is an openaccess article distributed under the terms of the Creative Commons Attribution 4.0 International license.

\section{INTRODUCTION}

Thalassemia major and few cases of intermedia are inherited diseases with dreaded complications requiring blood transfusions, even for mere survival. Unfortunately repeated transfusions come with a heavy price, leading to several co-morbid states resulting in morbidity and mortality along with significant reduction in quality of life. Inherited hemoglobinopathies, namely hemoglobin variants, thalassemia syndromes and their combinations show wide variation of prevalence in different regions and among different population. Globally $1.5 \%$ of population carry beta thalassemia gene. In India 30 million are beta thalassemia carriers and 7000 babies with beta-thalassemia major are born annually. ${ }^{1}$ South-East Asian countries account for $50 \%$ of world's thalassemia carriers and maximum Hemoglobin E (HbE) cases. HbE ( $\beta-26$ glutamine $\rightarrow$ lysine), a structural variant of haemoglobin, though asymptomatic singly, in combination with thalassemia trait may manifest as thalassemia minor, intermedia or major. ${ }^{2}$ In absence of cure, prevention remains the mainstay.
Hence, Government of India, implemented universally accepted assessment tools like screening tests for carrier and case detection at various stages like neonatal and premarital screening and other preventive interventional strategies, counselling sessions and awareness generation activities to ensure appropriate health behaviour of cases and carriers. Beta thalassemia screening program was launched nationwide. Sensitization programs were intensified, hemoglobin variant study for case and carrier detection was done using HPLC technique (High Performance Liquid Chromatography). ${ }^{1-2}$ Benefits of procedure and absence of risk associated was emphasized.

Premarital screening is presumed to reduce mortality and morbidity load of the disease. ${ }^{2}$ Legislative reforms making it mandatory, especially for adolescents, who are on verge of making reproductive choices are called for. Adolescence is a phase rather than a fixed time period when enormous physical and psychological changes occur along with changes in social perceptions and expectations. Health sector needs to play a sustainable role in addressing to their di-

Cite this article : Ghosh N, Chakrabarti I, Goswami BK. Study to Assess Prevalence of Hemoglobinopathies by HPLC among Class IX and X Students of a Rural Block, Darjeeling District, West Bengal. Int J Med Public Health. 2018;8(2):71-6. 
verse needs, helping them stay healthy and successfully complete their journey to adulthood. ${ }^{3}$ Perceived to be proactive and receptive to various screening programs and awareness generation activities, schools serve as receptive area for adolescents. ${ }^{4}$ Catering a mix of various racial groups and ethnicities, schools represent the existent local community. Adolescents, studying in secondary schools, particularly in rural areas are perceived to be better suited for assessment tests and are thus targeted for screening programs.

Assessment of hemoglobinopathy through school based approach is assumed to reflect current status of the area and help designing appropriate preventive interventional strategies to address the issues further.

Scientific literature revealed carrier rate of beta-thalassemia varied between $0-17 \%$ in different ethnic groups and documented proven relationship of hemoglobinopathies with ethnicity. ${ }^{5} \mathrm{HbE}$ have prevalence of $1-2 \%$ in West Bengal and is believed to be harboured by Rajbanshis, who comprise major ethnic group of local population. ${ }^{5}$

Segregated data regarding adolescents in this part of rural terrain is rare. Thus in aforesaid context and to add to the existing database, present study was conducted with the following objectives.

1. To determine prevalence of hemoglobinopathies among school going adolescents of class IX and X in the study area.

2. To find out association of hemoglobinopathies with other sociodemographic factors with special reference to any defined ethnic groups existing in the study area

3. Estimating prevalence of anemia among school going adolescents in study area

\section{MATERIALS AND METHODS}

\section{Study design, Setting, Subjects}

A descriptive cross-sectional study was conducted among all the government run co-education secondary schools of Naxalbari block, Darjeeling district, West Bengal, India. Study period was from November 2015 to August 2016 and field level data was collected for six months. It was intended to include all students of class IX and X studying in the 9 such schools, based on their current enrolment status. Estimated strength was 3205. However due to organizational and administrative issues, 7 schools could be studied. Estimated students were 2572 .

Those with history of documented hemoglobinopathy, absent on screening days despite prior sensitisation, receiving blood transfusion within last six weeks or priorly screened for hemoglobinopathies were excluded from study. Students unwilling to participate in the study, lacking guardian consent, unavailable or absent on screening days despite prior sensitisation were also excluded. Thus finally 1792 eligible subjects could be studied.

\section{Data collection and measurement}

Line listing of all eligible study subjects was done with help of school teachers. Briefing was done in schools two days prior to organizing screening camps clearly stating the benefit, intent and purpose of study. Sensitization was carried along with briefing to increase student participation, increase guardian consent and ensure support from school authorities. Relevant posters, pamphlets and other IEC materials were displayed and distributed. Holding counselling sessions by trained counsellors on screening days simultaneously was assured and ensured. Blood collection procedure was explained. No risk associated was emphasized. Queries were addressed.

Screening camps were held over 6 months. Dates were decided in accordance to operational feasibility of TCU and after consultation with concerned school authorities. Data was collected on prefixed dates among eligible study subjects by organizing screening camps in school premises.

\section{Socio-demographic variables}

Were recorded by interview method using a predesigned pretested semi-structured schedule from the eligible study subjects. Background characteristics elicited were age, gender, caste, religion, ethnicity (Rajbanshi, hilly tribes, adivasis, etc.), history of consanguineous marriages, family history of cases or carriers, history of blood transfusion or screening tests in past. Students were then subjected to blood tests for screening.

\section{Assessment of hemoglobinopathies}

Venous blood collection was done maintaining appropriate techniques and estimated by HPLC machine using recommended guidelines. Logistics and equipments for blood collection were taken to field. Blood was collected and transported to TCU with due care.

\section{Process of Blood Collection}

Trained paramedical staffs of TCU collected $5 \mathrm{ml}$ of venous blood in vials using EDTA as anticoagulant, transported them to TCU and ran them in cell counter (Sysmex KX 21) and HPLC machine (Variant, Bio- Rad, USA using beta thalassemia short program). Value of $3.6 \%$ of $\mathrm{HbA} 2 / \mathrm{E}$ fraction of hemoglobin was taken as cut off point for determining beta thalassemia trait and value of more than $10 \%$ was assumed to be $\mathrm{HbE}$. Blood was screened for hemoglobinopathies and anemia. Reports were handed over to highest school authorities within a month. Estimation of haemoglobin variant was done by HPLC. Recommended cut off points for different variants were considered using standard recommended guidelines. ${ }^{6-7}$

HPLC, the commonest tool for detecting cases and carriers has made estimation fast, reliable and reproducible with high sensitivity and specificity for identification and quantification of abnormal hemoglobin variants. However it couldn't detect $\alpha$ thalassemias. ${ }^{8}$ Mandatory prerequisite of accounting for clinical history, family history, complete blood count, PBS and nutritional anemia while interpreting chromatograms was a major limitation for the present study. ${ }^{8-9}$ Molecular studies is recommended for step wise upgradation of screening tests. Its unavailability was a major limitation for conclusive diagnosis in present study. ${ }^{1}$

Only those study subjects found positive were referred to TCU for further management. Family studies were done. TCU is a government endeavour and all equipments are regularly checked, assessed and kept functional. Quality control is stringently ensured and enforced.

\section{Assessment of anemia}

Collected blood was also tested in Automated cell counter for blood parameter estimation. ${ }^{6-7}$ Complete blood counts particularly Haemoglobin (g/dl), Hematocrit, RBC count, MCV, MCH, MCHC, RDW and Peripheral Blood Film Examinations were done.

\section{Information dissemination}

Awareness generation activities were conducted on sensitisation days. Knowledge on preventive measures for hemoglobinopathies was assessed. During sensitization sessions they were motivated for peer dissemination of information to 3 families and their performance was noted by selfreporting on screening days.

\section{Ethical consideration}

Ethical clearance from Institutional Ethics Committee, NBMCH was obtained. District Inspector of Schools and Chief Medical Officer of Health, Darjeeling district, Block Medical Officer of Health, Naxalbari block and highest school authority of concerned schools were intimidated about purpose of study and approval obtained. Informed voluntary written consent was taken. Anonymity and confidentiality of reports was ensured. Unique identification number was generated for each participant. 


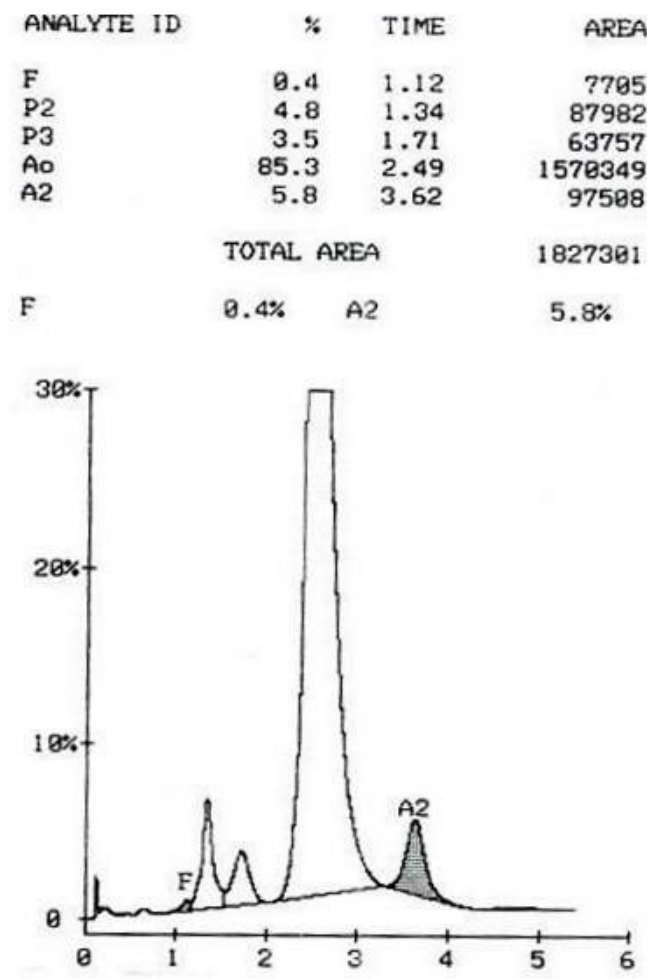

Figure 1: HPLC Chromatogram showing beta Thalassemia trait [BIORAD: Beta thal short program].

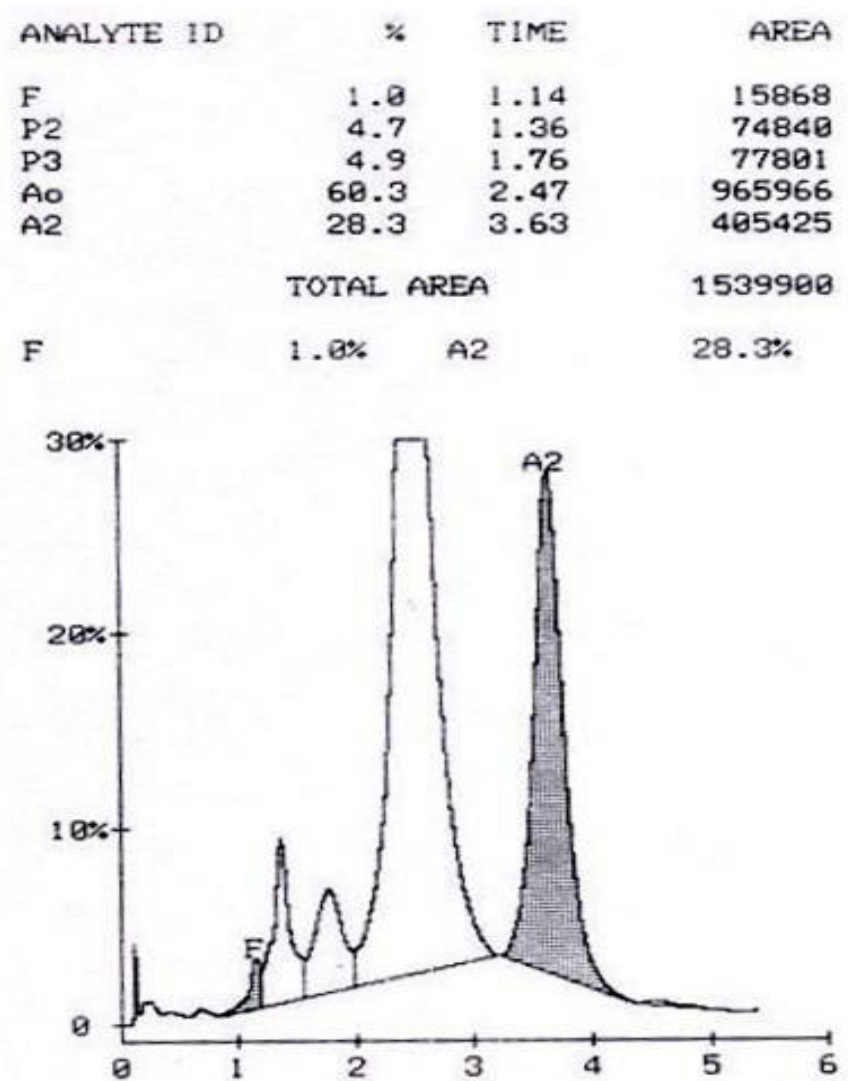

Figure 2: HPLC chromatogram showing Hemoglobin E trait [BIORAD: Beta thal short program].
Adolescents consented on their own behalf. ${ }^{10}$ It was assured that data will be used for academic and research purpose only.

\section{Data management and analysis}

Data was cleaned, checked for consistency, compiled and entered into Microsoft Xcel and analysed using principles of descriptive and inferential statistics using Statistical Package for Social Sciences version 20. Prevalence and proportion of specific attributes were calculated in percentages and association was tested by Chi square test. Data was presented in form of tables.

\section{RESULTS}

1792 eligible subjects were studied.

\section{Socio demographic characteristics}

Equal number of students participated from class IX and X, 49.9\% and $50.1 \%$ respectively. Background characteristics reveal $66.2 \%$ of study subjects were aged between 15-16yrs. Majority were boys (60.3\%), Hindus (69.2\%) and Rajbanshis (56.3\%). 25.3\% study subjects were Muslims and $15.9 \%$ and $11.1 \%$ belonged to hill tribes and non hilly tribes like adivasis respectively. $12.9 \%$ study subjects were offspring's of consanguineous marriages and among 4.1\% (73 subjects) having positive family history, 19 had thalassemic siblings whereas 54 had relatives requiring repeated blood transfusions for survival. 96 study subjects (5.3\%), mostly girls, were married. (Table 2 )

\section{Hemoglobinopathy and its variants}

Prevalence of hemoglobinopathies was found to be $44.5 \%$ (798 subjects). Major variants were $\mathrm{HbE}(22.6 \%)$, beta thalassemia trait (9.8\%), E-beta thalassemia (7.3\%) followed by $\mathrm{HbS}, \mathrm{HbD}, \mathrm{HbJ}$ in traces (Table 1). Lone inconclusive case needed parental study before final diagnosis. $\mathrm{HbE}$ hemoglobinopathies (E-beta thalassemia, E trait, EE disease) were found in 581 subjects, prevalence being $32.4 \%$. However Sickle cell trait and S-beta thalassemia heterozygous was not reported. Figures 1 and 2 show chromatograms of beta thalassemia trait and Hemoglobin E traits respectively.

\section{Association of hemoglobinopathies with other socio- demographic variables}

Abnormal haemoglobin variants were found distributed maximally among 14-15years (54.4\%) and among Hindus (47.9\%), followed by Muslims and Christians. However they were equally distributed among

\begin{tabular}{|c|c|}
\hline Hemoglobin variants & Number ( Percentage) \\
\hline Normal hemoglobin & $994(55.5)$ \\
\hline Abnormal variants & $798(44.5)$ \\
\hline - $\quad \mathrm{Hb}$ E trait & $406(22.6)$ \\
\hline - Beta thal trait & $175(9.8)$ \\
\hline - E beta thal & $131(7.3)$ \\
\hline - $\quad$ EE disease & $44(2.4)$ \\
\hline - $\quad \mathrm{Hb} \mathrm{S}$ & $27(1.5)$ \\
\hline - $\quad \mathrm{Hb} \mathrm{D}$ & $12(0.6)$ \\
\hline - $\quad \mathrm{Hb} \mathrm{J}$ & $2(0.1)$ \\
\hline - Inconclusive & $1(0.05)$ \\
\hline
\end{tabular}




\begin{tabular}{|c|c|c|c|}
\hline \multirow[t]{2}{*}{ Socio-demographic Variables } & Hemoglobinopathy absent $(\mathrm{N}=994)$ & Hemoglobinopathy present $(\mathrm{N}=798)$ & Statistical test \\
\hline & $\mathrm{N}(\%)$ & $\mathrm{N}(\%)$ & \\
\hline \multicolumn{4}{|c|}{ Age (in years) } \\
\hline $14-15(n=333)$ & $152(45.6)$ & $181(54.4)$ & \multirow{3}{*}{$\chi^{2}$ for linear trend $=.52, \mathrm{df}=2, \mathrm{p}=.46$} \\
\hline $15-16(n=1187)$ & $715(60.2)$ & $472(39.8)$ & \\
\hline $16-17(n=272)$ & $127(46.7)$ & $145(53.3)$ & \\
\hline \multicolumn{4}{|c|}{ Gender } \\
\hline Boys $(\mathrm{n}=1081)$ & $602(55.7)$ & $479(44.3)$ & \multirow[t]{2}{*}{$\chi^{2}=.05, \mathrm{df}=1, \mathrm{p}=.81$} \\
\hline Girls $(n=711)$ & $392(55.1)$ & $319(44.9)$ & \\
\hline \multicolumn{4}{|c|}{ Religion } \\
\hline Hindu $(\mathrm{n}=1241)$ & $647(52.1)$ & $594(47.9)$ & \multirow[t]{3}{*}{$\chi^{2}$ for linear trend $=25.23, \mathrm{df}=2, \mathrm{p}=.00$} \\
\hline Muslim ( $\mathrm{n}=454)$ & $273(60.1)$ & $181(39.9)$ & \\
\hline Christian $(\mathrm{n}=97)$ & $74(76.3)$ & $23(23.7)$ & \\
\hline \multicolumn{4}{|c|}{ Ethnicity } \\
\hline Rajbanshi (n=1009) & $517(51.2)$ & $492(48.8)$ & \multirow[t]{4}{*}{$\chi^{2}$ for linear trend $=8.81, \mathrm{df}=2, \mathrm{p}=.00$} \\
\hline Hill tribes $(n=285)$ & $163(57.2)$ & $122(42.8)$ & \\
\hline Nonhilly tribes $(\mathrm{n}=198)$ & $156(78.8)$ & $42(21.2)$ & \\
\hline Others $(n=300)$ & $158(52.7)$ & $142(47.3)$ & \\
\hline \multicolumn{4}{|c|}{ Positive family history ( having thalassemic siblings or relatives requiring blood transfusion) } \\
\hline Positive $(n=73)$ & $11(15.1)$ & $62(84.9)$ & $\chi^{2}=50.29, \mathrm{df}=1, \mathrm{p}=.00$ \\
\hline Negative $(\mathrm{n}=1719)$ & $983(57.2)$ & $736(42.8)$ & \\
\hline \multicolumn{4}{|c|}{ History of consanguineous marriage among parents } \\
\hline Present $(n=232)$ & $65(28.1)$ & $167(71.9)$ & $\chi^{2}=1.31, \mathrm{df}=1, \mathrm{p}=.00$ \\
\hline Absent $(n=1560)$ & $929(59.6)$ & $631(40.4)$ & \\
\hline
\end{tabular}

(Number in parenthesis indicate percentage)

\begin{tabular}{|c|c|c|c|c|}
\hline Ethnicity & $\mathrm{Hb}$ E variants & Other variants (Non $\mathrm{HbE}$ variants) & Normal Hemoglobin & Statistical test \\
\hline Rajbanshis $(\mathrm{n}=1009)$ & $417(41.3)$ & $75(7.4)$ & $517(51.3)$ & $\begin{array}{c}\chi^{2} \text { for linear trend }=47.2 \text {, } \\
\qquad \mathrm{df}=2, p=0.00\end{array}$ \\
\hline
\end{tabular}

(Number in parenthesis indicate percentage)

boys and girls, $44.3 \%$ and $44.9 \%$ respectively. Among Rajbanshis, 48.8\% suffered from hemoglobinopathies. However very few cases were noted among Nepali population. Abnormal haemoglobin variants were found in $84.9 \%$ of study subjects having documented positive family history. Among off springs of consanguineous marriages, $71.9 \%$ had hemoglobinopathies. Chi square test revealed hemoglobinopathies to be significantly associated with positive family history, consanguineous marriages and ethnicity $(p<0.00)$. (Table 2$)$

\section{Association of Rajbanshis and $\mathrm{HbE}$ hemoglobinopathies}

Among Rajbanshis, $\mathrm{HbE}$ variants (comprising of $\mathrm{HbE}$ trait, EE disease and E-beta thalassemia) were found in $41.3 \%$ subjects, whereas non $\mathrm{HbE}$ variants and normal haemoglobin was found in $7.4 \%$ and $51.3 \%$ cases respectively. Other ethnicities reported $20.9 \% \mathrm{HbE}$ variants. Moreover, significant association was also found to exist between Rajbanshis and HbE hemoglobinopathies $(p<0.00)$. (Table 3)

\section{Estimation of anaemia}

Prevalence of anemia among study subjects was $45.2 \%$. Among girls, majority were anaemic $(74.8 \%)$ whereas among boys only $25.8 \%$ were anemic. Among Rajbanshis, $67.1 \%$ were anemic whereas among diagnosed 798 cases of hemoglobinopathies, $78.7 \%$ had coexistent anemia. (Table 4). Anemia was classified according to mild, moderate, severe using the recommended guidelines. Prevalence of mild and moderate anemia was $40 \%$ and $5.1 \%$ respectively, prevalence being more among those affected with hemoglobinopathies. However only 2 cases were found to have severe anemia, both had coexistent hemoglobinopathies. (Table 5) 


\begin{tabular}{|c|c|c|}
\hline \multirow[t]{2}{*}{$\begin{array}{c}\text { Socio-demographic } \\
\text { variables }\end{array}$} & $\begin{array}{l}\text { Anemia absent } \\
\qquad(n=981)\end{array}$ & $\begin{array}{l}\text { Anemia present } \\
\qquad(\mathrm{n}=\mathbf{8 1 1})\end{array}$ \\
\hline & $\mathbf{N}(\%)$ & $\mathrm{N}(\%)$ \\
\hline \multicolumn{3}{|c|}{ Age (in years) } \\
\hline $14-15(n=333)$ & $202(60.7)$ & $131(39.3)$ \\
\hline $15-16(n=1187)$ & $635(53.5)$ & $552(46.5)$ \\
\hline $16-17(n=272)$ & $144(52.9)$ & $128(47.1)$ \\
\hline \multicolumn{3}{|c|}{ Gender } \\
\hline Boys $(n=1081)$ & $802(74.2)$ & $279(25.8)$ \\
\hline Girls $(n=711)$ & $179(25.2)$ & $532(74.8)$ \\
\hline \multicolumn{3}{|c|}{ Religion } \\
\hline Hindu $(\mathrm{n}=1241)$ & $845(68.1)$ & $396(31.9)$ \\
\hline Muslim ( $\mathrm{n}=454)$ & $73(16.1)$ & $381(83.9)$ \\
\hline Christian $(\mathrm{n}=97)$ & $63(64.9)$ & $34(35.1)$ \\
\hline \multicolumn{3}{|c|}{ Ethnicity } \\
\hline Rajbanshi (n=1009) & $332(32.9)$ & $677(67.1)$ \\
\hline Hill tribes $(n=285)$ & $264(92.6)$ & $21(7.4)$ \\
\hline $\begin{array}{l}\text { Non hilly tribes } \\
\quad(\mathrm{n}=198)\end{array}$ & $144(72.7)$ & $54(27.3)$ \\
\hline Others $(n=300)$ & $241(80.3)$ & $59(19.7)$ \\
\hline \multicolumn{3}{|c|}{ Presence of hemoglobinopathies among study subjects } \\
\hline Present $(n=798)$ & $170(21.3)$ & $628(78.7)$ \\
\hline Absent $(\mathrm{n}=994)$ & $811(81.6)$ & $183(18.4)$ \\
\hline
\end{tabular}

\begin{tabular}{|c|c|c|c|c|}
\hline Hemoglobinopathy & $\begin{array}{c}\text { Anemia } \\
\text { absent }\end{array}$ & $\begin{array}{c}\text { Mild } \\
\text { anemia }\end{array}$ & $\begin{array}{c}\text { Moderate } \\
\text { anemia }\end{array}$ & $\begin{array}{l}\text { Severe } \\
\text { anemia }\end{array}$ \\
\hline Present $(n=798)$ & $170(9.5)$ & $558(31.1)$ & $68(3.8)$ & $2(0.1)$ \\
\hline Absent $(n=994)$ & $811(45.2)$ & $160(8.9)$ & $23(1.3)$ & $0(0.0)$ \\
\hline
\end{tabular}

$16.1 \%$ (289 study subjects) had correct knowledge regarding prevention of thalassemia and 740 subjects (41.3\%) reported performing peer dissemination of information after the sensitization program.

\section{DISCUSSION}

Preventable diseases like hemoglobinopathies with potentially fatal outcomes and dreaded complications need stringent control measures. Various studies have been planned and conducted in various parts of the nation to throw light on its various aspects.

Present study concluded prevalence of hemoglobinopathies as $44.5 \%$ with $\mathrm{HbE}$ as the major variant. Other studies similarly revealed $\mathrm{HbE}$ as commonest variant in north-eastern India with a prevalence of 7-50\%, while another cross sectional study in North Bengal found prevalence of hemoglobinopathies among $0-20 \mathrm{yrs}$ as $30.5 \% .{ }^{1}$ A pilot study among Sindhi community found $\mathrm{HbE}$ prevalence as $19.26 \% .{ }^{11}$ However all reasons for increased prevalence hemoglobinopathies in present study was difficult to comprehend.

Inability to perform family study for the lone inconclusive case was a limitation. Chromatograms needed to be interpreted in the light that nutritional anemia and other factors were not accounted before screening tests, as recommended. ${ }^{8}$

Present study found relatively lower prevalence of hemoglobinopathies among Muslims and tribals, in contrast to other studies. Other states noted higher prevalence of hemoglobinopathies among them. ${ }^{1,12}$ Assam recorded a higher morbidity load of hemoglobinopathies, due to incorporating various linguistic and ethnically diverse population and migrants. ${ }^{12}$ Clustering of hemoglobinopathies was found in small pockets, attributable to small population size, caste endogamy, consanguinity, virtual lack of medical facilities and natural barriers like rivers, forests, etc. ${ }^{1,5}$ Migration of people and marriages between communities has led to its wide prevalence. $\mathrm{HbS}, \mathrm{HbD}, \mathrm{HbJ}$ were found in trace amounts in present study, a finding echoed by other studies as well. HbD was found commonly in Punjab, $\mathrm{HbS}$ in tribal areas. ${ }^{1,5}$

$\mathrm{HbE}$ preponderance among hilly tribes and in Assam and Tripura regions hint a lineage simulation, acculturation and inter-caste marriages between Rajbanshis and these states. ${ }^{5,12-13}$ Earlier studies in blocks of Darjeeling district also found low prevalence of hemoglobinopathies among Nepali population. Being mostly converts from Rajbanshis, Muslims exhibit more preponderance for the disease due to intermixing and narrowing down of differences with Rajbanshis genetically. ${ }^{1}$

Present study revealed Rajbanshis as the majority (56.3\%) and also noted their significant association with $\mathrm{HbE}$ hemoglobinopathies, the commonest variants. Similiar to present study $\mathrm{HbE}$ was noted to be harboured mostly by Rajbanshis, the major ethnic group of local terrain. ${ }^{1,5}$ Significant association between them was documented by other studies as well.

Segregated data on adolescents was revealed by the present study. Rajbanshis and $\mathrm{HbE}$ hemoglobinopathies both being commonly prevalent among adolescents in the study area, advocating and implementing premarital screening becomes mandatory. Hemoglobinopathies were also significantly associated with positive family history and history of consanguineous marriages, a finding similar to a pilot study conducted among antenatal women. ${ }^{5}$

Present study noted that among subjects diagnosed anaemic, majority were girls (65.6\%), a finding shared by other studies. ${ }^{5,12}$ Adolescent girls need enlightenment on importance of intergenerational life cycle approach, importance of balanced diet and awareness generation on pertinent issues.

Differentiating between types of anemia was beyond scope of study. Presuming anemia in rural terrain as nutritional, a possibility exists that $\mathrm{HbA} 2$ values were interpreted as false low and hemoglobinopathy exists more. ${ }^{1,8}$ Beta thalassemia trait $(9.8 \%)$ in present study, pose a potential threat, since in combination with $\mathrm{HbE}$, the commonest variant noted, they may lead to thalassemia. ${ }^{1}$

A large community based study revealed iron-deficiency anemia simulating $\mathrm{HbE}$ hemoglobinopathies in double heterozygous states, commonly in Rajbanshis and Muslims. Iron supplements having no role, inadvertent use in high risk region needs revision to avoid iron overload. ${ }^{1,4}$

$16.1 \%$ and $41.3 \%$ adolescents in present study were aware about prevention of hemoglobinopathies and proactively participated in peer dissemination of information respectively. Another study noted 56.2\% Bengalis residing in a high risk area to have good knowledge on thalassemia, but were unaware about its types. Extensive awareness generation activities among masses were conducted by them. Carrier couples were diagnosed and consanguineous marriages between carriers avoided. Special attention was given to high risk families. ${ }^{14}$ Screening camps, psycho-genetic counsellings, premarital screenings were organized in schools, relevant materials were displayed and peer dissemination of information was carried out by them similar to the present study. 


\section{CONCLUSION}

Hemoglobinopathies among school going adolescents in the study area was substantially high with $\mathrm{HbE}$ and beta thalassemia trait comprising the major variants. $\mathrm{HbE}$ hemoglobinopathies have higher prevalence in Rajbanshis, as compared to other ethnic groups. Moreover, HbE hemoglobinopathies are found to be significantly associated with Rajbanshis, the major ethnic group. Prevalence of anemia is alarmingly high among study subjects and girls were more anemic than boys. School going adolescents were receptive to screening programs and proactively participated in information dissemination and other awareness generation activities. However a larger study is recommended.

\section{CONFLICT OF INTEREST}

The authors declare no conflict of interest.

\section{ABBREVIATIONS}

NBMCH: North Bengal Medical College and Hospital, Hb: Hemoglobin; RBC: Red blood Corpuscles; MCV: Mean Corpuscular Volume; MCH: Mean Corpuscular Hemoglobin; MCHC: Mean Corpuscular Hemoglobin Concentration; RDW: Red cell Distribution Width, thal: Thalassemia; IEC: Information Education Communication.

\section{REFERENCES}

1. Goswami BK, Pramanik R, Chakraborty S, Pal PP, Banerjee S, Bandopadhyay A. Spectrum of Hemoglobin Variants in the Population of Northern Region of West Bengal: An Ethnogenetic Proposition. J Family Med Prim Care. 2014;3(3):219-23.

2. Verma IC, Saxena R, Thomas E, Jain PK. Regional distribution of $\beta$-thalassemia mutations in India. Hum Genet. 1997;100:109-13.
3. Ministry of Health and Family Welfare, India. Implementation guide on RCH-II: adolescent reproductive sexual health strategy. New Delhi, India: NRHM;2006 [cited 2014 Nov 24]. Available at:www. nrhm.gov.in/nhm

4. Sur D, Mukhopadhyay SP. Prevalence of thalassemia trait in the state of West Bengal. J Indian Medical Association. 2006;104(1):11-5.

5. Ghosh N, Chakrabarti I, Chakraborty M, Goswami BK. A community based pilot study on prevalence of hemoglobinopathies among the antenatal women in a rural area of Darjeeling district, West Bengal. Int J Med Public Health. 2013;3(2):107-10.

6. Handbook on Variant Hemoglobin Testing System. Bio-Rad Laboratories India Pvt. Ltd.

7. K.PARK'S Textbook of Preventive and Social Medicine. $23^{\text {nd }}$ ed. Prem nagar Jabalpur: M/s Banarsidas Bhanot Publishers. 2015;621-23.

8. Rao S, Kar R, Gupta SK, Chopra A, Saxena R. Spectrum of haemoglobinopathies diagnosed by cation exchange-HPLC and modulating effects of nutritional deficiency anaemias from North India. Indian J Med Res. 2010;132(5):513-9.

9. Mondal SK, Dasgupta S, Mondal S, Das N. Spectrum of thalassemias and hemoglobinopathies in West Bengal: A study of 90,210 cases by cation exchange high-performance liquid chromatography method over a period of 8 years. J Appl Hematol. 2014;5(3):91-5.

10. Ruiz-Canela M, Lopez-del Burgo C, Carlos S, Calatrava M, Beltramo C, Osorio A, et al. Operational research with adolescents: a framework for the management of the parental permission. BMC Medical Ethics. 2013;14(1):2.

11. Bhanvadia VM, Chavda A, Mehta D, Satwara A, Parmar M, Sheikh SS. Prevalence of hemoglobinopathy in Sindhi community of Jamnagar, Gujrat: A pilot study. Int Journal of Medicine and Public Health. 2015;5(4):349-52.

12. Baruah MK, Saikia M, Baruah A. Pattern of hemoglobinopathies and thalassemias in upper Assam region of North Eastern India: High performance liquid chromatography studies in 90000 patients. Indian J Pathol Microbiol. 2014;57(2):236-43.

13. Mandal PK, Maji SK, Dolai TK. Present scenario of hemoglobinopathies in West Bengal, India: An analysis of a large population. Int J Med Public Health. 2014;4(4):496-9.

14. Behera SK, Panja S, Adak DK. Thalasemia control by awareness: A study among Bengalee population of south 24 Pargana, West Bengal, India. The Internationa Journal of Indian Psychology 2016;3(2):53-9. 